\title{
Business French and Translation in the Era of Google Translate: Variations on the Action-based Approach in Language Courses
}

\author{
Mittler, Sylvia and Sonina, Snejina
}

Centre for French and LInguistics, University of Toronto Scarborough, Canada

\begin{abstract}
In this article we outline our practices for the inclusion of electronic translation devices in specialized French language courses and reflect upon the changing landscape of language teaching. We describe how the use of Google Translate can increase students' awareness of linguistic, stylistic, and cultural differences in our culturally and linguistically diverse classrooms. Although we characterize our didactic approach as action-based, we differentiate our use of this approach from its common use in general language courses and point out the usefulness of intellectualizing it based on our use of Google Translate in work-place-oriented courses. Furthermore, we use our experience with action-based approaches and translation devices to answer the following questions: why are students still learning languages; what are the language skills that they are interested in; and what is the role of a language teacher in this new world of quasi-magic linguistic tools.
\end{abstract}

Keywords: Technology in language learning; Teaching experiences; Learning for employment; Action-based approach. 


\section{Introduction}

A few months ago, the French professors in our department received an e-mail entitled "Google Translate" from a colleague in panic. The point of the missive was that we should indicate clearly on our syllabi that students are not allowed to use Google Translate for their French assignments and that such use will be considered plagiarism.

While it is obvious that the use of a translation device for essays would not reflect students' knowledge of French, the idea of simply banning Google Translate from our teaching practices did not sit well with us. Since we teach Business French and French Translation, both courses preparing students for using French in their future careers, we agreed that we could not ignore the existence of free translation devices in our changing world. These rapidly improving devices can, we believe, be helpful in professional and everyday life; instead of banning their use in our courses and carrying on as if it were still the twentieth century, we would rather consider how to include them, and more important, how to teach students to use them effectively.

Our conversations on the subject and our experiments with Google Translate in our teaching practices led us to more serious questions. What is the role of a language teacher in a world where everyone has means of translation available at their fingertips? Since the Internet can provide immediate help with translation, what language skills should we emphasize in our teaching? Why would anyone still wish to learn a foreign language when tools for translation and even voice recognition are available?

In this article we will share our observations about students' goals for learning French, our best practices for the inclusion of language practice and translation devices in our specialized courses, and our reflections about the changing landscape of language teaching.

\section{Why study French at all?}

A survey conducted in September 2017 among the students of our French program showed that most students want to study French for practical purposes: they are mainly interested in courses dealing with language and culture (In what areas would you like to see new courses offered? - Languages - 63; Culture - 56; Linguistics - 36; Literature - 33, Pedagogy - 23); when choosing their specialization they prefer Languages and Linguistics (What stream would you be most interested in within a French Major? - Languages \& Linguistics - 55, Culture \& Literature - 24; Pedagogy - 12).

On the UTSC campus, this distribution reflects pragmatic reasons for studying French: in Canada, a major or a minor in the French language added to a resume may mean a better chance of getting a better job. We believe that the distribution of interest we describe is consistent with a general trend toward dropping enrollment in the Humanities. Most 
university students study languages not to enjoy literary masterpieces but to acquire a practical tool to improve their chances for a successful career. Courses like Business French and French Translation are designed specifically to help them in this endeavor.

\section{Do we teach content or language?}

Although the main focus of Business French is supposed to be on the French language, or rather a French language subset used in the work context, the course is perceived as content-based by many students. For most students who major in French all business and finance content is totally new. Not even the students from our Management Program are familiar with all of the concepts discussed in this course for mastering business-related vocabulary and writing practices. However, in order to understand business language it is necessary to understand the meaning of professional terms and expressions. So, in practice, we use much of our class time teaching the basic concepts of entrepreneurship, the stock market, and banking en français. Of course, what students need to master is the usage of the French language in a work context, and thus the main object of study is the specialized business vocabulary and the subset of syntactic patterns used in business correspondence. However, since the vocabulary is inseparable from content and writing patterns reflect cultural preferences, the outcome of the course is threefold: students learn a great deal about the world of business and finances, about cultural differences in French and English correspondence, and about specific linguistic patterns characteristic of business French.

After the basics are mastered in Business French, French Translation courses refine language skills, teaching how to preserve maximum fidelity to original meaning in translation while always retaining linguistic clarity. It is axiomatic that no single, perfect translation exists for anything, but instead variations according to socio-cultural background, style, register, and so on. Students seated behind computers work on informative, non-literary texts and soon learn to think strategically when translating: to approach translation in terms of the sentence and its main syntactic clusters, to identify difficult words or phrases in a sentence before they start, to choose a French adjective with a clear, defined meaning over a synonym that possesses different meanings or even shades of meaning in different contexts, to remember clarity mostly dictates "less is more", and to always home in on meaning as opposed to its mere linguistic envelope in order to flexibly substitute a French noun for an English verb, or replace English-language military-domain metaphors with culturally appropriate French culinary ones. Practical application of concepts is thus continuous; so is comparison and contrast of Hallidayan language model elements such as register and lexico-grammar in order to learn differing French and English patterns of transitivity, emotive modality, thematic structure and cohesion (Halliday, 2004). Students examine a variety of texts that throw linguistic differences and cultural particularities in their path randomly as they move, say, from a financially-oriented text to 
one dealing with information technology, public health, agribusiness or plastics recycling. They can use on-line dictionaries like Linguee, terminology banks like Termium, even grammar correctors, and quickly learn to verify on their own what Google and other services give them by checking for usage within French and then re-using Google to translate back to English.

To use the vocabulary of Lightbrown (2014), our Business French courses are more "meaning-focused" while our French Translation courses are more "language-focused" (p.68-9); the latter draw students' attention to accurate use of the material acquired in the former. In both course types, however, the conceptually and culturally determined objects of study require a different approach to teaching than the approaches used in general language practice courses.

\section{How do we teach?}

The main approach used in our teaching of both Business French and French Translation is meaning-driven, which in this case represents a real cross between content-based, projectbased, and task-based approaches. These approaches had been used in such courses long before the action-based approach - described as related to all the three by van Lier (2007) became popular in language teaching and spread to universities. In fact, similar approaches called "work-based learning" or "action learning" have been used since the 1980s in training for business (Lester \& Costly, 2010; Trehan \& Pedler, 2011), public services (Rigg \& Richards, 2006), and community development (Zuber-Skerritt, 2013).

Since 2003, the Business French course has been taught with particular attention to student needs, a perspective which is also consistent with the action-based approach. Such attention is a must on our campus, which represents an extreme case of "growing cultural, racial and linguistic diversity" (Gearon et al., 2009, p.3) that has been discussed in North-American didactic literature for decades. However, on top of this, students in Business French come from different programs and specializations. The diversity of students' backgrounds prompted us to divide them into groups according to their specializations and future careers: managers, teachers, health and wellness counselors, etc.. Each group was asked to create an imaginary venture according to their specialization (a small business, a private school, a health and wellness centre, etc.) and then to make presentations and produce business letters according to the chapters of the textbook and the corresponding "problems" of their imaginary ventures.

Initially, textbook chapters and their vocabulary constituted the basis for students' creativity. However, since textbook prices kept climbing (Berg's Parlons affaires reached $\$ 150$ ) and the on-line materials kept multiplying and improving, we considered teaching a 
course without a textbook. Now we had more freedom in arranging subjects according to the logical development stages of the imaginary ventures. The separate tasks became a continuous narrative - a course-long project.

With the continual growth of students' ventures and their knowledge of business terminology, the concept of scaffolding, emphasized in the action-based approach, came into play naturally. Each group would progress from the simple activities of the first class, in which students first learn the main types of ventures, consider the possibility of forming their own imaginary venture, learn some basic principles of business writing, and then collectively compose a short missive to a future consultant, to the more sophisticated tasks of the last class, in which students discuss investment opportunities for the "millions" they have "gained" and write a detailed letter to their investment advisors.

Scaffolding as defined by Lightbrown (2014) - "supporting the communicative efforts of another speaker, especially a language learner, by providing vocabulary or partial sentences that the speaker can 'build' on" (p.146) - has always been an essential part of teaching French for business purposes. For example, in the textbook by Besnard and Elkabas (1997), which was used at the very beginning of this century long before action-based didactics, each chapter provided exactly that - vocabulary and partial sentences. It was the instructor's task to relate the "scaffolds" to students in the appropriate time and manner. However, students' creativity often was restricted by their limited knowledge of French vocabulary and grammar. The arrival of translation tools and omnipresent Wi Fi helps to overcome these limitations.

\section{How does Google Translate help us to teach more effectively?}

Translation tools available on the Internet help to grow the autonomy of the learner, which, as van Lier insists, is the "defining feature" of scaffolding (Lier, 2007, p.62). Nowadays, students can find the information needed to fill in the structures provided through scaffolding quickly and easily. Thus these translation means provide another type of support - a support complementary to teacher-supplied scaffolding. In Business French the in-class instruction provides an explanation of concepts all too often unknown or foreign, whether for cultural or syntactic reasons - and then adds thematically organized terminology followed by the partial syntactic frames for business correspondence. Google Translate complements this with the terminology specific to the students' field of specialization and to their particular business "venture". In the case of practical translation classes, because it is taught and actively learned together as a game of defensive strategy, much as in popular video games, the intensive application of concept to practice results in students' enjoyment, increased familiarity with verification techniques and finally, increased sophistication and accuracy in translating. Even translation students with limited 
knowledge of French, once they learn what to look for in a Google translation and how to check it, can find Google Translate a useful scaffolding tool. Faced with a translation model they can correct, refine and improve by themselves, they have fun using their creativity to improve their knowledge. There is nothing that a resourceful student cannot express in French with the help of these matching tools.

Since success comes so easily, students gain confidence and enjoy using French. They appreciate the convenience and usefulness of translation tools, but at the same time they quickly become aware of their conceptual and cultural shortcomings when they review their translations in class with the help of the teacher. Below, we give a few concrete examples of the facilitation of students' learning of vocabulary, syntactic structures, and cultural particularities, as carried out in Business French and French Translation respectively.

In Business French facilitation for learning vocabulary consists in pointing out main difficulties and helping with memorization. Natasha Tokowicz, a professor of Psychology and Linguistics, distinguishes three types of difficulties in second language lexical processing: "cognate translations [...], concrete and abstract words, and words that are translation-ambiguous across languages in that they have more than one translation" (2015, p.75). In the case of true cognates, it is important to highlight the gender of the corresponding French word and to advise students to type in a word with an indefinite article in order to get the desired cognate: thus "a business venture" is translated "une entreprise" and students can use this word correctly right away. As for the false cognates, Google Translate has no problem with their correct translation; therefore in class it can be used for a game of cognates - true or false, while in projects and in life it can be used for a quick check of any translation.

The words that Google Translate does not get right consistently are translation-ambiguous. So in this case as well there is a special trick to teach: since translation algorithms use word distribution frequency and set phrases to "guess" the right meaning, it is always safer to type in a complete sentence than a single word in order to get a proper equivalent. For example, Google Translate renders the English word "position" wrongly for business contexts even in short phrases: "an excellent position > une excellente position, an important position > une position importante". However, it gets it right in a complete sentence: "I am interested in this position > Je suis intéressé par ce poste".

In translation courses, not cross-checking Google Translate's rendering of "Experts predict a $10 \%$ rise in exports" as "Les experts prédisent une hausse de $10 \%$ des exportations" nets a student the correct nouns for "rise" and "exports", but the wrong choice of verb and preposition: "prédisent" is used for crystal-ball-style predictions and should read "prévoient", while "de $10 \%$ des exportations" indicates a rise of only $10 \%$ of total exports and in the interest of clarity should read "de $10 \%$ dans les exportations". Google's amusing 
literal translation of a sentence in a text on malware, "Forget stealing your credit card number, this malicious software does much more!", tells the reader to forget stealing his/her own credit card - «Oubliez de voler votre numéro de credit, ce logiciel malveillant fait beaucoup plus! »- because Google can't identify the evaluative comparison being made between card-theft and the software's much greater capacity for harm. A meaning-sensitive student, however, will arrive at "Le vol de votre carte de credit n'est rien" or " $n$ 'est qu'une bagatelle", that is, "credit card theft is nothing", followed by a translation of "compared to".

To help students with memorization, we recommend different approaches for concrete and abstract words and different on-line tools for practice. For memorizing concrete words, it is a good idea to use "image" in a Google search and then organize the images thematically. For example, pictures of different types of paperclips for the subject "office materials" illustrate the meaning of the French words and draw attention to their morphology (Fig.1).

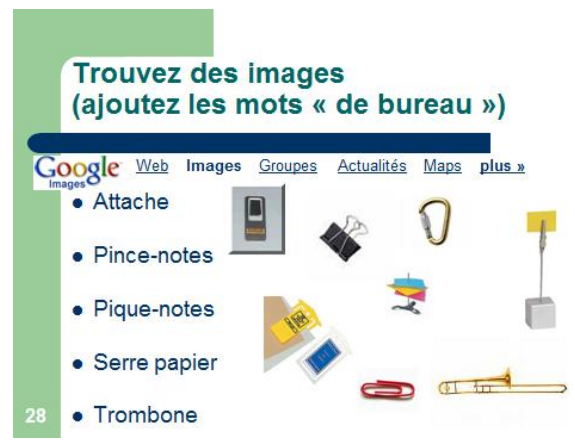

Figure 1. Google images for types of paperclips.

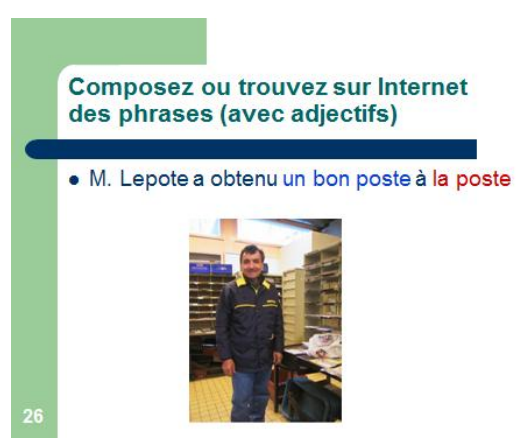

Figure 2. Sentence and illustration.

Pictures are less effective for abstract words, which need to be accompanied by sentences: in Fig. 2 the picture illustrates the sentence, drawing attention to the different meanings of the French word "poste" - "position" if masculine but "post office" if feminine. There is also a way to organize abstract words into semantically-related clusters, or even "word association networks" similar to those studied by Meara (2009, p.59-64); students thus find help with understanding meaning and memorization through association. Translation devices and electronic dictionaries are useful for the tasks of constructing such clusters and finding synonyms and antonyms.

Translation devices render syntactic structures perfectly well. However, they do not always get cultural differences right. By now, Google Translate has learned to differentiate between the informal "tu" and the formal "vous" in French. Once again, the key is to feed the translation device as much context as possible. In a short sentence not marked for any official situation, Google will render "you" as "tu" - "Could you do it? > Pourrais-tu le faire?"; but when we use any word from business vocabulary it will change "tu" to "vous" "Could you send me a sample? > Pourriez-vous m'envoyer un échantillon?". 
However, Google Translate misses cultural differences in some important business formulas, including formulas of address and farewell. In formal letters, it translates "Dear Mr. Smith" as "Cher Mr Smith" instead of the simple and standard French "Monsieur" used without "cher" or "Smith". It correctly translates "Sincerely" as "Cordialement", unlike most anglophone students who use the false (in this situation) cognate "Sincèrement". But since "Cordialement" is not used in formal letters that require a longer standard formule de politesse at the end, cultural differences become more important than standard grammar in the teaching of French for professional use. They loom equally large in translation at any level - perhaps larger than is commonly realized. That said, a solid intellectual understanding of grammatical phenomena is also absolutely necessary in both types of classes we discuss. For example, students need to understand the principal difference between conditional and indicative modes in order to render the English "could" correctly and to choose the proper mode for a letter:

Generally, the use of translation devices helps to improve overall course outcome. We base our finding on the results of 300 translation students over 5 years, as well as 300 in Business French over 15 years. Before Google Translate, students would reach the end of Business French with a collection of business letter samples and a good knowledge of the business vocabulary and syntactic patterns that might help them in their future career; in French Translation they would be expert in consulting dictionaries and trusty grammar manuals for key vocabulary and syntactic patterns culled from language in general. Further scaffolding aid eluded them in both environments. Nowadays, having used the same samples and patterns with the help of Google in work-like simulations in class and in athome projects, students finish both types of meaning-centred courses with the confidence that, given resources, they will be perfectly functional in any francophone work environment.

\section{Conclusion: why, what, and how to learn with translation devices}

Usefulness is the aspect of our courses that students appreciate the most because comments like "One of the first classes that actually taught me useful information required for real life use of the French language" and "More specialized courses like this should be offered at UTSC" are the most frequent in course evaluations. While such remarks confirm practical goals in learning languages with the help of Google Translate, further student comments on overall learning experience and available assistance elucidate two other questions that we asked in the introduction.

The comments from Business French indicate a shift in the skills sought in language learning: most students valued the speaking practice and especially the attention to their pronunciation that became a focus of our in-class activities once we delegated most time- 
consuming undertakings to the machines. In Translation Courses, students appreciated their increased knowledge of usage as well as their ability to discriminate shades of meaning and stylistic differences. Importantly, in both types of courses students deeply appreciated our helping with memorization and increasing their awareness of linguistic, stylistic and cultural differences. For although we use didactics linked to an action-based approach, our courses emphasize intellectual understanding. It is their growth in such understanding, whether in pronunciation or in stylistic choices, that students value the most as their learning outcomes. Therefore, we see our role as language teachers as providing guidance for more conscious mastering of linguistic and cultural phenomena - for the learning that will help students use translation devices effectively.

\section{References}

Rigg, C. \& Richards, S. (Eds.). (2006) Action learning, leadership and organizational development in public services. London: Routledge.

Berg, R.-J. (2013) Parlons affaires!: Initiation au français économique et commercial. Boston: Thomson Heinle.

Besnard, C.\& Elkabas, C. (1997) Pratique des affaires. Toronto : Canadian Scholars' Press.

Gearon, M., Miller, J. \& Kostogriz, A. (Eds.). (2009) Culturally and Linguistically Diverse Classrooms: New Dilemmas for Teachers. Bristol ; Buffalo, NY : Multilingual Matters.

Halliday, M.A.K. \& Matthiessen,C. (2004) An Introduction to Functional Grammar. London: Arnold.

Hatim, B. (2009) "Translating text in context", in J. Munday (ed.) The Routledge Companion to Translation Studies. Abingdon and New York: Routledge, pp. 36-53.

Lester, S. \& Carol, C. (2010) "Work-based learning at higher education level: value, practice and critique" in Studies in Higher Education, Vol. 35 (No. 5), 561-575.

Lier, L. van. (2007) “Action-based Teaching, Autonomy and Identity" in Innovation in Language Learning and Teaching, Vol. 1 (No. 1), 46-65.

Lightbown, P.M. (2014) Focus on content-based language teaching. Oxford : Oxford University Press.

Littlemore, J. (2009) Applying Cognitive Linguistics to Second Language Learning and Teaching. Houndmills, Basingstoke; New York : Palgrave Macmillan.

Meara, P. (2009) Connected words: word associations and second language vocabulary acquisition. Amsterdam ; Philadelphia : John Benjamins Pub. Co.

Pym, A. (2010) Exploring Translation Theories. Abingdon and New York: Routledge.

Tokowicz , N. (2015) Lexical processing and second language acquisition. New York, NY: Routledge.

Trehan, Kiran and Pedler, Mike. (2011) "Action learning and its impact" in Action Learning: Research and Practice, Vol 8 ,(No 3), 183 - 186.

Zuber-Skerritt, Ortrun. (2013) Lifelong Action Learning for Community Development. [S.1.] : SensePublishers. 